\title{
Comparison of measurements of neuroretinal rim area between confocal laser scanning tomography and planimetry of photographs
}

\author{
Jost B Jonas, Christian Y Mardin, Anselm E Gründler
}

\begin{abstract}
Background-To compare neuroretinal rim area measurements by confocal scanning laser tomography and planimetric evaluation of optic disc photographs.

Methods-For 221 patients with primary and secondary open angle glaucoma, 72 subjects with ocular hypertension, and 139 normal subjects, the optic disc was morphometrically analysed by the confocal scanning laser tomograph HRT (Heidelberg retina tomograph) and by planimetric evaluation of stereo colour optic disc photographs.

Results-Absolute rim area and rim to disc area were significantly $(p<0.0001)$ larger with the HRT than with planimetric evaluation of photographs. Differences between the two methods were significantly $(p<0.01)$ larger in normal eyes with small cupping than in normal eyes with large cupping, and differences were significantly $(p<0.01)$ larger in glaucomatous eyes with marked nerve damage than in glaucomatous eyes with moderate nerve damage. Coefficients of correlations between rim measurements of both methods were $R^{2}=0.60$ for rim to disc area and $R^{2}=0.33$ for absolute rim area. Planimetric measurements of rim area correlated significantly $(p<0.05)$ better than HRT determinations of rim area with mean visual field defect and retinal nerve fibre layer visibility.

Conclusions-Measurements of absolute rim area and rim to disc area are significantly larger with the HRT compared with planimetry of disc photographs. Differences between both methods depend on disc area, cup size and glaucoma stage. The reason may be that the HRT measures the retinal vessel trunk as part of the neuroretinal rim. The differences between both methods, which should be taken into account if disc measurements performed by both methods are compared with each other, may not influence the main advantage of the HRT - that is, morphological follow up examination of patients with glaucoma.

(Br F Ophthalmol 1998;82:362-366)
\end{abstract}

The neuroretinal rim of the optic nerve head is the intrapapillary extension of the optic nerve fibres. Since glaucoma typically leads to a loss of neuroretinal rim, measurement of the area of neuroretinal rim is of great importance in the morphometric analysis of the optic disc for quantification of glaucomatous optic nerve damage. $^{12}$

Several techniques can be employed to determine the size of the neuroretinal rim. For an approximate clinical estimation of the neuroretinal rim size, the horizontal and vertical diameters of the optic disc and optic cup can be measured using an ophthalmoscopic lens and a slit lamp where the length of the beam can be adjusted to the diameters of the disc and cup. ${ }^{3}$ The neuroretinal rim area results are the difference of disc area minus cup area which are calculated by the formula: horizontal diameter $\times$ vertical diameter $\times \pi \div 4$. For follow up examinations and scientific studies, however, a more precise measurement of the neuroretinal rim is mandatory. This can be achieved by taking stereo photographs of the optic disc, plotting the margins of the optic disc and cup, and analysing morphometrically the plottings after correction of the ocular and camera magnification. ${ }^{124}$ Instead of photographs, laser scan images can be obtained using the sophisticated technique of confocal laser scanning tomography. ${ }^{5-12}$ Since this is a computerised method that is partially independent of the subjective evaluation by an examiner, it offers advantages that have so far been unachievable. Its clinical importance is exemplified by the fact that a change from subjective planimetry of optic disc photographs to a computerised morphometry of the optic nerve head is comparable with the switch from conventional manual perimetry to modern automated strategies of visual field examination. Since confocal scanning laser tomography is a new method, one is interested in its reproducibility, which has already been evaluated, ${ }^{5-9}$ and its consistency with established techniques.

This was the purpose of the present study comparing neuroretinal rim measurements performed by the Heidelberg retina tomograph (HRT) as the confocal laser scanning tomograph with determinations of the neuroretinal rim by planimetric evaluation of stereo optic disc photographs. To compare the clinical validity of the two techniques, both methods were correlated with the mean visual field defect and the visibility of the retinal nerve fibre layer.

Patients and methods

In all, 221 patients with primary open angle glaucoma and secondary open angle glaucoma, 72 subjects with ocular hypertension, and 139 
Table 1 Composition of the study groups (mean (SD))

\begin{tabular}{llll}
\hline & $\begin{array}{l}\text { Normal group } \\
(n=139)\end{array}$ & $\begin{array}{l}\text { Ocular hypertensive } \\
\text { group }(n=72)\end{array}$ & $\begin{array}{l}\text { Total glaucoma group } \\
(n=221)\end{array}$ \\
\hline Women/men & $78 / 61$ & $31 / 41$ & $104 / 117$ \\
Age (years) & $43.2(13.4)$ & $46.1(11.4)$ & $48.8(12.3)$ \\
Refractive error (D) & $-0.62(2.42)$ & $0.00(2.20)$ & $-0.92(2.32)$ \\
Range & -7.5 to +7.0 & -5.25 to 6.50 & -7.85 to +5.5 \\
\hline
\end{tabular}

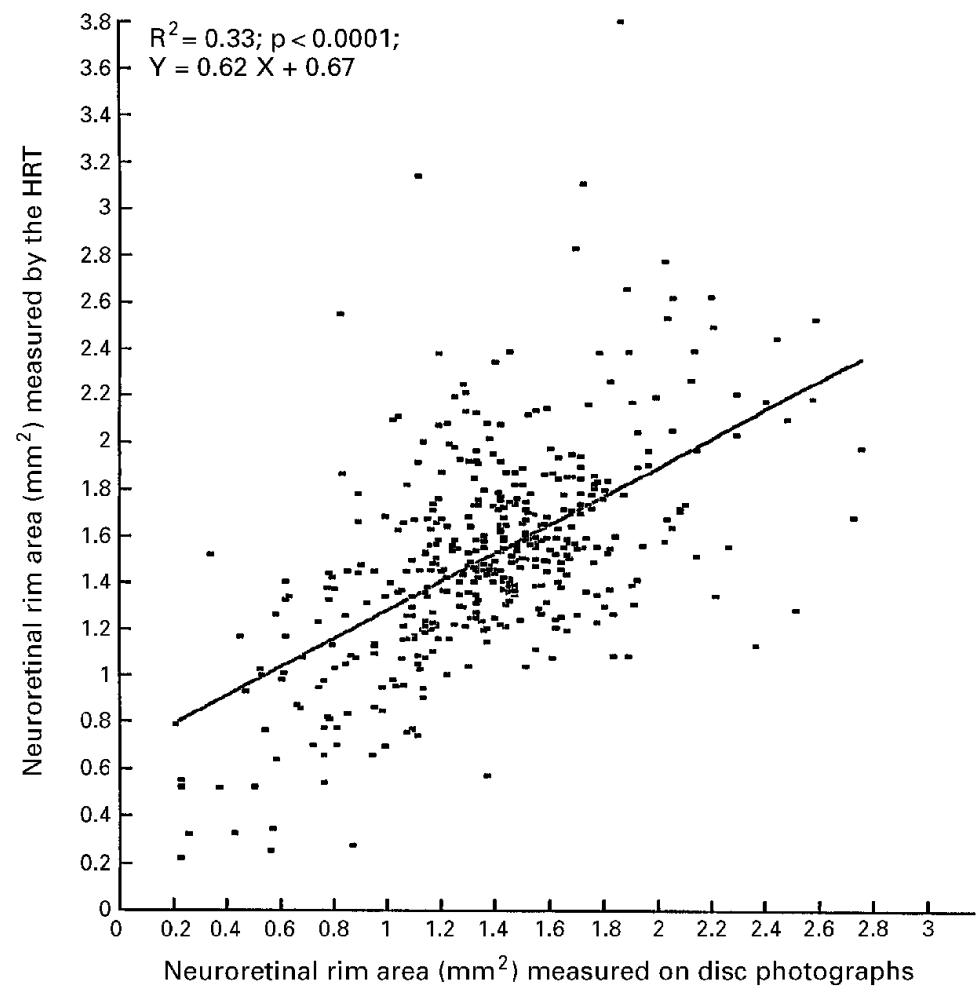

Figure 1 Scattergram showing the correlation between measurements of neuroretinal rim area by the HRT and rim area determination by planimetry of optic disc photographs in 221 patients with primary and secondary open angle glaucoma, 72 subjects with ocular hypertension, and 139 normal subjects.

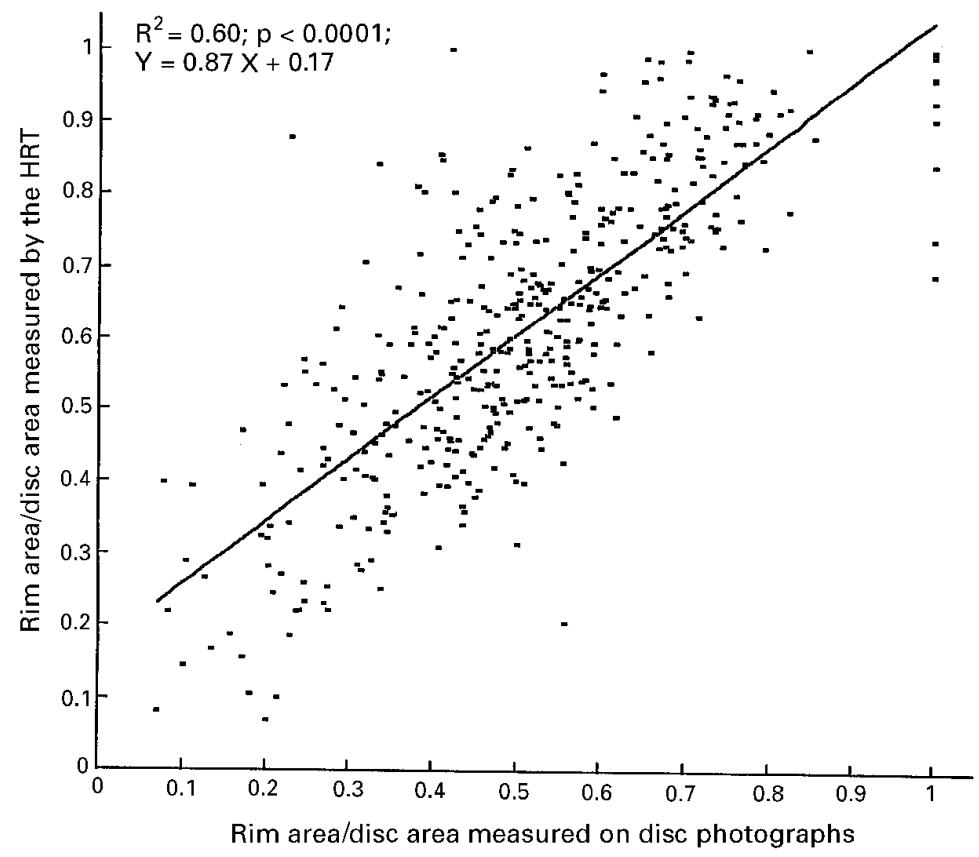

Figure 2 Scattergram showing the correlation between measurements of the ratio of neuroretinal rim area to disc area performed by the HRT and by planimetry of optic disc photographs. normal subjects were included in the study (Table 1). Only one randomly selected eye per subject and patient was taken for statistical analysis. Eyes with a myopic refractive error exceeding -8.0 dioptres were excluded because of their different optic disc morphology. ${ }^{13}$

Criteria for the diagnosis of open angle glaucoma were an open anterior chamber angle and typical glaucomatous changes of the optic nerve head and/or glaucomatous abnormalities of the visual field. Glaucomatous changes of the optic nerve head included a glaucomatous shape of the neuroretinal rim, cup to disc ratios being vertically higher than horizontally, optic disc haemorrhages, and localised or diffuse retinal nerve fibre layer defects. Glaucomatous perimetric defects examined in the осторUs G1 program consisted of elevated global visual field indices and a distribution of the perimetric defects typical for glaucoma such as Bjerrum scotomata, nasal steps, and deep paracentral scotomata.

In the primary open angle glaucoma group, the reason for an elevation of intraocular pressure was unknown. In the group with secondary open angle glaucoma, the increase of intraocular pressure to values above $21 \mathrm{~mm} \mathrm{Hg}$ was due to pseudoexfoliative glaucoma and pigmentary glaucoma. The ocular hypertensive subjects had intraocular pressure readings of more than $21 \mathrm{~mm} \mathrm{Hg}$ or history of it, an unremarkable optic disc, and normal visual fields. The normal subjects were recruited from the administrative university staff who were asked to serve as control subjects, or they were patients who attended the hospital for diseases in the contralateral eyes that was not included in the study. These diseases, such as rhegmatogenous retinal detachment, did not primarily affect the optic nerve. In the normal eyes, there was no history of ocular disease, intraocular pressure was less than $21 \mathrm{~mm} \mathrm{Hg}$, visual acuity was equal to or higher than $20 / 25$, and slit lamp biomicroscopy and ophthalmoscopy were unremarkable.

For all eyes, $15^{\circ}$ colour stereo optic disc transparencies had been taken using a telecentric fundus camera. The disc slides were projected in a scale of 1 to 15 . The margins of the optic disc and optic cup were plotted on paper and evaluated planimetrically. The border between the neuroretinal rim and the cup of the disc was defined by contour and not by pallor. The method has already been described in detail. ${ }^{214}$ The ocular and camera magnification was corrected according to Littmann's technique taking into account the anterior corneal curvature and the refractive error of the eye. ${ }^{4}$

For 81 glaucoma patients and 88 normal subjects, $60^{\circ}$ red-free photographs of the retinal nerve fibre layer had been taken as already described. ${ }^{15} 16$ We used a $60^{\circ}$ fundus camera, a high power illumination, a blue filter, and a low sensitive film with high resolution. Instead of paper prints diapositives were developed. These slides were projected with a magnification of 15 times after maximal defocusing of the projector. The area of the blurred image of the optic disc was covered, the projector was 


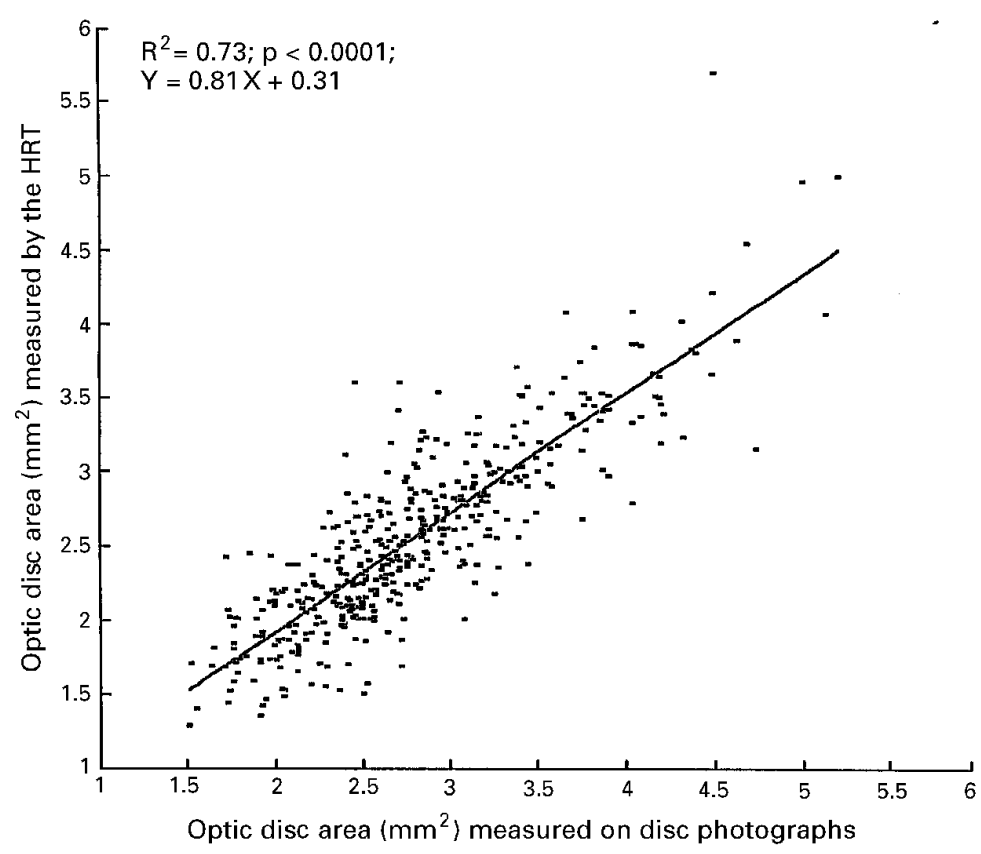

Figure 3 Scattergram showing the correlation between measurement of the optic disc area by the HRT and determination of the optic disc area by planimetric evaluation of optic disc photographs. ard deviation of the topographic images was 28.3 (SD 10.3) $\mu \mathrm{m}$. The border of the disc was outlined manually with the help of optic disc photographs projected simultaneously. According to software version 1.11 , the reference plane for the delineation of the optic cup from the neuroretinal rim was the level $50 \mu \mathrm{m}$ beneath the contour line in the temporal segment, 4-10 degrees below the horizontal axis of the disc. HRT examination and optic disc photography were performed at the same day.

Since quantitative data of the optic disc expressed in absolute size units such as $\mathrm{mm}^{2}$ differ between various laboratories and techniques employed, ${ }^{12} 68$ 14 17-19 $^{17}$ the measurements of the neuroretinal rim area were additionally calculated as ratio of rim area to disc area.

\section{Results}

Taking all eyes included in the study, absolute neuroretinal rim area and rim to disc area were significantly $(p<0.0001$; Wilcoxon matched pairs test) larger if measured by the HRT than if determined by planimetric evaluation of disc photographs (mean 1.51 (SD 0.45) $\mathrm{mm}^{2}$ rim area versus $1.37(0.42) \mathrm{mm}^{2}$ rim area; and 0.62 (0.20) rim to disc area versus $0.51(0.17) \mathrm{rim}$ to disc area) (Figs 1 and 2). The difference between both methods was more marked for the data expressed as rim to disc area, since the optic disc was measured significantly smaller by the HRT than by the planimetric method (2.56 (0.63) $\mathrm{mm}^{2}$ versus $2.79(0.66) \mathrm{mm}^{2}$; $\mathrm{p}<0.0001$; Wilcoxon matched pairs test) (Fig 3).

In normal eyes with disc cupping, the differences between both methods were negatively correlated with the size of the optic cup (Pearson's correlation coefficient $\mathrm{R}=-0.18 ; \mathrm{p}$ $=0.0001)$. The smaller the optic cup, the more pronounced was the difference between the larger HRT values and the smaller planimetric data. Corresponding to the physiological correlation between cup area and optic disc size, ${ }^{20}{ }^{21}$ the differences between both methods were also significantly $(\mathrm{p}<0.05)$ and negatively correlated with the area of the optic disc.

In normal eyes with no cupping, rim to disc area ratio measurements equalled 1.0 and were congruent in both methods. It follows from the definition of neuroretinal rim as difference of disc area minus cup area.

Table 2 Correlation coefficients, $R, p$ values, and equations of linear regression lines for the correlation between neuroretinal rim area measurements and other variables

\begin{tabular}{lll}
\hline Variable & Planimetry of disc photographs & HRT measurements \\
\hline Mean visual field defect & $\mathrm{R}=-0.58 ; \mathrm{p}<0.0001$ & $\mathrm{R}=-0.51 ; \mathrm{p}<0.0001$ \\
& $\mathrm{Y}=-0.06 \mathrm{X}+1.49$ & $\mathrm{Y}=-0.06 \mathrm{X}+1.62$ \\
Square root of the mean visual defect & $\mathrm{R}=-0.64 ; \mathrm{p}<0.0001$ & $\mathrm{R}=-0.52 ; \mathrm{p}<0.0001$ \\
& $\mathrm{Y}=-0.24 \mathrm{X}+1.58$ & $\mathrm{Y}=-0.21 \mathrm{X}+1.68$ \\
& $\mathrm{R}=0.32 ; \mathrm{p}<0.0001$ & $\mathrm{R}=0.19 ; \mathrm{p}=0.01$ \\
Visibility of the retinal nerve fibre layer & $\mathrm{Y}=0.02 \mathrm{X}+1.13$ & $\mathrm{Y}=0.01 \mathrm{X}+1.35$ \\
"Neuroretinal rim area defect" correlated with mean visual field defect & $\mathrm{R}=0.58 ; \mathrm{p}<0.0001$ & $\mathrm{Y}=0.52 ; \mathrm{p}<0.0001$ \\
& $\mathrm{Y}=0.06 \mathrm{X}+0.09$ & $\mathrm{R}=0.52 ; \mathrm{p}<0.0001$ \\
"Neuroretinal rim area defect" correlated with the square root of the & $\mathrm{R}=0.64 ; \mathrm{p}<0.0001$ & $\mathrm{Y}=0.20 \mathrm{X}-0.08$ \\
mean visual field defect & $\mathrm{Y}=0.24 \mathrm{X}+0.00$ & $\mathrm{R}=-0.46 ; \mathrm{p}<0.0001$ \\
Rim area/disc area correlated with mean visual field defect & $\mathrm{R}=-0.52 ; \mathrm{p}<0.0001$ & $\mathrm{Y}=-0.02 \mathrm{X}+0.66$ \\
& $\mathrm{Y}=-0.02 \mathrm{X}+0.56$ & $\mathrm{R}=-0.46 ; \mathrm{p}<0.0001$ \\
Rim area/disc area correlated with the square root of the mean visual & $\mathrm{R}=-0.56 ; \mathrm{p}<0.0001$ & $\mathrm{Y}=-0.08 \mathrm{X}+0.69$ \\
field defect & $\mathrm{Y}=-0.09 \mathrm{X}+0.59$ & \\
\end{tabular}


In the glaucoma group, the differences between the larger HRT values and the smaller planimetric data additionally depended on the stage of the disease. In glaucomatous eyes with a mean visual field defect of less than $4 \mathrm{~dB}$, the differences were significantly $(p<0.05$; Wilcoxon Mann-Whitney test) smaller than in eyes with a mean perimetric loss of more than $4 \mathrm{~dB}$.

Correlating the values of both methods with the mean visual field defect and visibility of the retinal nerve fibre layer, respectively, correlation coefficients were significantly $(\mathrm{p}<0.05$ and $\mathrm{p}<0.005$, respectively) ${ }^{22}$ higher for the planimetric rim determinations than for the HRT measurements (Table 2). If the square root of the mean visual field defect instead of the original perimetric value was correlated with the rim area measurements, the correlation coefficients increased for the planimetric rim determinations and were again significantly $(p<0.001)^{22}$ higher for the planimetric method than for confocal laser scanning tomography (Table 2). Correspondingly, if the ratio of rim area to disc area or a new variable the "neuroretinal rim area defect" instead of the neuroretinal rim area were correlated with the square root of the mean visual field defect, the correlation coefficients were significantly $(\mathrm{p}<0.001)$ higher for the planimetric evaluation of disc photographs than for the rim determination by the HRT (Table 2). The new variable "neuroretinal rim area defect" was calculated as "neuroretinal rim area defect" = expected rim area - measured rim area. "Expected rim area" was defined as: expected rim area $=$ "A" $\times$ optic disc area + " $B$ ". This was the equation of the regression line for the correlation between neuroretinal rim area and optic disc area in the normal subjects of this study. For the planimetric method, "A" was equal to 0.182 , and " $\mathrm{B}$ " was equal to 1.075 (with a correlation coefficient $\mathrm{R}=0.31$ and $\mathrm{p}<0.0001$ ). For the HRT method, "A" was equal to 0.122 , and " $\mathrm{B}$ " was equal to 1.296 (with a correlation coefficient $\mathrm{R}=0.34$ and $\mathrm{p}<0.0001)$. The scattergrams including the regression lines for both methods were similar to those already published. ${ }^{14}$

\section{Discussion}

Comparing both methods in measuring neuroretinal rim size reveals that the HRT determinations of the absolute rim area and of the rim to disc area ratio are significantly larger than planimetric measurements on disc photographs (Figs 1 and 2). It confirms a recent study in which both methods were compared in their ability to determine the shape of the neuroretinal rim in a smaller cohort of patients and subjects. ${ }^{23}$

Several reasons can be responsible for the discrepancy between the confocal laser scanning tomographic method and the planimetry of disc photographs. The most likely reason is that the HRT measures parts of the central retinal vessel trunk as if it belongs to the neuroretinal rim even if there is no nerve fibre tissue beneath the vessels. It is the result of the algorithm of the HRT which defines the neuroretinal rim as all the area inside the peripapillary contour line above the reference plane. The latter is determined $50 \mu \mathrm{m}$ beneath the mean level of the contour line in a sector located 4-10 degrees below the temporal horizontal disc pole (HRT software version 1.11). In this definition, all points lying inside the contour line above the reference plane are considered to be neuroretinal rim. It does not distinguish between different types of tissue. Since the retinal vessels of the optic nerve head cross the reference plane, they are partially included in the measurement of the neuroretinal rim area. It is in contrast with the definition of the neuroretinal rim that is generally used for the ophthalmoscopic and planimetric determination of the neuroretinal rim area. ${ }^{24}$ In the latter definition, retinal vessels are considered to belong to the neuroretinal rim only, if neuroretinal rim tissue with retinal ganglion axons is underlying them.

Another reason for the differences between the two methods can be that for both techniques the optic disc border has to be outlined manually in an interactive step. Since the optic disc margin can better be detected on disc photographs than on HRT images, a different outlining of the optic disc may also partially explain the discrepancy between the two methods. In the present study, however, disc photographs were projected when the disc was outlined on the HRT image. Other reasons for differences in rim and disc area measurements between both methods may be a difference in the correction of the image magnification by the ocular media, or a misalignment between patient and fundus camera or laser scanner ${ }^{25}$ which has recently been emphasised.

The variation in the definition of the neuroretinal rim explains why the difference in the relative rim area measurements between both methods enlarged with increasing glaucomatous optic nerve damage as determined perimetrically. The relative proportion of the retinal vessels on the rim measurements by the HRT is larger in eyes with little neuroretinal rim tissue left than in normal eyes or eyes with early glaucoma. Since the loss of neuroretinal rim as measured on disc photographs outweighs the diminution of the retinal vessel calibre in eyes with advanced glaucoma, ${ }^{26}$ the differences between both methods enlarge with increasing glaucomatous optic nerve damage.

The varying definition of neuroretinal rim may be the reason why the difference in rim area measurements between the two methods depends on the optic cup size in normal eyes. In normal eyes with small optic discs and no cupping, the neuroretinal rim covers the whole disc and the rim to disc area ratio is 1.0 in both methods. In normal eyes with cupping, the difference between both methods is larger in eyes with small discs and small cups than in eyes with large discs and large cups. The reason is that in eyes with disc cupping the percentage of retinal vessel area on total disc area decreases with increasing disc size. This has to be taken into account when rim measurements of both methods are compared with each other. 
Addressing the question which of the two methods may better reflect the degree of glaucomatous optic nerve damage, we correlated the rim measurements of both methods with the mean visual field defect and with the visibility of the retinal nerve fibre layer (Table 2 ). The correlation coefficients were significantly higher for the planimetric rim determinations than for the measurements by the HRT (Table 2). It suggests that planimetric rim area measurements may correlate better than HRT measurements with other examinations showing the degree of glaucomatous optic nerve damage. It should not make one forget the many clinical and practical advantages offered by the HRT, such as the three dimensional assessment of the optic cup, the determination of the contour of the retinal nerve fibre layer in the parapapillary region, the high reproducibility, its probable superiority in follow up examinations, the fast availability of the results, and the fact that the HRT does not require full pupillary dilatation and that the HRT examination as semiautomatic technique can partially be delegated to technicians..$^{5-12} 27$ It further has to be stressed that the present study compares rim measurements between both methods only in a cross sectional manner; it does not say anything about the comparability of results in follow up examinations of patients with glaucoma where the main advantages of the HRT are located.

Supported by Deutsche Forschungsgemeinschaft (Klinische Forschergruppe "Glaukome", grant no Na 55/6-2). The authors have no proprietary interest in any instruments described here.

1 Betz Ph, Camps F, Collignon-Brach J, Lavergne G, Weekers R. Biometric study of the disc cup in open-angle glaucoma Graefes Arch Clin Exp Ophthalmol 1982;218:70-4.

2 Airaksinen PJ, Drance SM. Neuroretinal rim area and retinal nerve fiber layer in glaucoma. Arch Ophthalmol 1985;103:203-4

3 Jonas JB, Papastathopoulos K. Ophthalmoscopic measurement of the optic disc. Ophthalmology 1995;102: 1102-6.

4 Littmann H. Zur Bestimmung der wahren Größe eines Objektes auf dem Hintergrund des lebenden Auges. Klin Monatsbl Augenheilkd 1982;180:286-9.

5 Dreher AW, Tso PC, Weinreb RN. Reproducibiity of topographic measurements of the normal and glaucomatous graphic measurements of the normal and glaucomatous
optic nerve head with the laser tomographic scanner. Am $\mathcal{f}$ Optic nerve head with the laser

6 Burk ROW, Rohrschneider K, Takamoto T, Völcker HE, Schwartz B. Laser scanning tomography and stereophoto- grammetry in three-dimensional optic disc analysis. Graefes Arch Clin Exp Ophthalmol 1993;231:193-8.

7 Rohrschneider K, Burk ROW, Kruse FE, Völcker HE. Reproducibility of the optic nerve head topography with a new laser tomographic scanning device. Ophthalmology 1994;101:1044-9.

8 Janknecht P, Funk J. Optic nerve head analyser and Heidelberg retina tomograph: accuracy and reproducibility of topographic measurements in a model eye and in volunteers. Br f Ophthalmol 1994;78:760-8.

9 Chauhan BC, LeBlanc RP, McCormick TA, Rogers JB. Test-retest variability of topographic measurements with confocal scanning laser tomography in patients with glaucoma and control subjects. Am $\mathcal{F}$ Ophthalmol 1994;118: glauco 15 .

10 Brigatti L, Caprioli J. Correlation of visual field with scanning confocal laser optic disc measurement in glaucoma. Arch Ophthalmol 1995;113:1191-4.

11 Zangwill L, Shakiba S, Caprioli J, Weinreb RN. Agreement between clinicians and a confocal scanning laser ophthalmoscope in estimating cup/disk ratio. Am f Ophthalmol 1995;119:415-21

12 Uchida H, Brigatti L, Caprioli J. Detection of structural damage form glaucoma with confocal laser image analysis. Invest Ophthalmol Vis Sci 1996;37:2393-401.

13 Jonas JB, Gusek GC, Naumann GOH. Optic disk morphometry in high myopia. Graefes Arch Clin Exp morphometry in high myopia.

14 Jonas JB, Gusek GC, Naumann GOH. Optic disc, cup and neuroretinal rim size, configuration, and correlations in normal eyes. Invest Ophthalmol Vis Sci 1988;29:1151-8. (Correction: Invest Ophthalmol Vis Sci 1992;33:474-5.)

15 Airaksinen PJ, Nieminen H. Retinal nerve fiber layer photography in glaucoma. Ophthalmology 1985;92:877-9.

16 Jonas JB, Schiro D. Normal retinal nerve fiber layer visibility correlated to rim width and vessel caliber. Graefes Arch Clin Exp Ophthalmol 1993;231:207-11.

17 Tuulonen A, Airaksinen PJ. Optic disc size in exfoliative, primary open angle, and low-tension glaucoma. Arch Ophhalmol 1992;110:211-3.

18 Burk ROW, Rohrschneider K, Noack H, Völcker HE. Are large optic nerve heads susceptible to glaucomatous damage at normal intraocular pressure? A threedimensional analysis using laser scanning tomography. Graefes Arch Clin Exp Ophthalmol 1992;230:552-60.

19 Chi T, Ritch R, Stickler D, Pitman B, Tsai C, Hsieh FY. Racial differences in optic nerve head parameters. Arch Ophthalmol 1989;107:836-9.

20 Bengtsson B. The variation and covariation of cup and disc diameters. Acta Ophthalmol 1976;54:804-8.

21 Caprioli J, Miller JM. Optic disc rim area is related to disc size in normal subjects. Arch Ophthalmol 1987;105:1683-5.

22 Williams EF. The comparison of regression variables. 7 Roy Stat Soc (Series B) 1959;21:396-9.

23 Dichtl A, Jonas JB, Mardin CY. Comparison between laser tomographic scanning evaluation and photographic measurement of the neuroretinal rim. Am $\mathcal{f}$ Ophthalmol 1996;121:494-501.

24 Jonas JB, Airaksinen PJ, Robert Y. Definitionsentwurf der intra- und parapapillären Parameter für die Biomorphometrie des Nervus opticus. Klin Monatsbl Augenheilkd 1988;192:621.

25 Orgul S, Cioffi GA, Bacon DR, Van Buskirk EM. Sources of variability of topometric data with the scanning laser ophthalmoscope. Arch Ophthalmol 1996;114:161-4.

26 Jonas JB, Nguyen XN, Naumann GOH. Parapapillary retinal vessel diameter in normal and glaucoma eyes. I 1599-603.

27 Bartz-Schmidt KU, Sengersdorf A, Esser P, et al. The cumulative normalised rim/disc area ratio curve. Graefes Arch Clin Exp Ophthalmol 1996;234:227-31. 